\title{
Fragility assessment of existing low-rise steel moment-resisting frames with masonry infills under mainshock-aftershock earthquake sequences
}

\author{
Luigi Di Sarno ${ }^{1}$ D . Jing-Ren $\mathrm{Wu}^{1}$
}

Received: 17 September 2020 / Accepted: 10 March 2021 / Published online: 26 March 2021

(c) The Author(s) 2021

\begin{abstract}
This paper presents the fragility assessment of non-seismically designed steel moment frames with masonry infills. The assessment considered the effects of multiple earthquakes on the damage accumulation of steel frames, which is an essential part of modern performance-based earthquake engineering. Effects of aftershocks are particularly important when examining damaged buildings and making post-quake decisions, such as tagging and retrofit strategy. The procedure proposed in the present work includes two phase assessment, which is based on incremental dynamic analyses of two refined numerical models of the case-study steel frame, i.e. with and without masonry infills, and utilises mainshockaftershock sequences of natural earthquake records. The first phase focuses on the undamaged structure subjected to single and multiple earthquakes; the effects of masonry infills on the seismic vulnerability of the steel frame were also considered. In the second phase, aftershock fragility curves were derived to investigate the seismic vulnerability of infilled steel frames with post-mainshock damage caused by mainshocks. Comparative analyses were conducted among the mainshock-damaged structures considering three post-mainshock damage levels, including no damage. The impact of aftershocks was then discussed for each mainshock-damage level in terms of the breakpoint that marks the onset of exceeding post-mainshock damage level, as well as the probability of exceeding of superior damage level due to more significant aftershocks. The evaluation of the efficiency of commonly used intensity measures of aftershocks was also carried out as part of the second phase of assessment.
\end{abstract}

Keywords Existing steel frame $\cdot$ Masonry infills $\cdot$ Fragility analysis $\cdot$ Aftershocks

Jing-Ren Wu

jingren.wu@liverpool.ac.uk

1 Department of Civil Engineering and Industrial Design, School of Engineering, University of Liverpool, Liverpool L69 3GH, UK 


\section{Introduction}

Existing buildings in seismic-prone areas are usually exposed to sequential earthquakes, in which a mainshock is accompanied by several aftershocks that originate near its rupture zone and have smaller magnitudes than the mainshock (Raghunandan et al. 2005). Many seismic events in recent decades (e.g., Niigata, Japan in 2004, L'Aquila, Italy in 2009, Christchurch, New Zealand in 2011 and Central Italy in 2016) have shown that aftershocks can have great impact on the seismic performance of existing buildings, resulting in severe damage accumulation and even collapse of structures that are already significantly damaged during the mainshocks. Therefore, it is of vital importance to conduct quick postquake assessment of damaged structures, which is aimed at evaluating the structural residual strength to resist aftershocks and making appropriate decisions regarding re-occupancy and repairing. (Yeo and Cornell 2005). To this end, it is necessary to investigate the effects of earthquake sequences on the seismic behaviour of structures.

Previous research has put great effort into the study of the impact of earthquake sequences on the behaviour of structures (e.g., Hatzigeorgiou 2010a, b; Di Sarno 2013; Di Sarno and Amiri 2019). For instance, Hatzigeorgiou (2010a) investigated the influence of earthquake sequences on the ductility demand of an SDOF structure and concluded that the ductility demand in the case of earthquake sequences was noticeably increased compared to the case of single earthquakes. Another study by Di Sarno (2013) compared the response spectra of single and multiple earthquakes and found that multiple ground motions tended to result in higher spectral acceleration for structures with short fundamental period and low ductility, as well as higher inelastic deformation demands than single earthquakes.

Some previous studies have particularly focused on the seismic performance of steel moment frames under earthquake sequences (Amadio et al. 2002; Lee and Foutch 2004; Li and Ellingwood 2007; Loulelis et al. 2012; Ruiz-García and Negrete-Manriquez 2011; Li et al. 2014; Ruiz-García and Aguilar 2015; Ruiz-García et al. 2018). Amadio et al. (2002) investigated the effects of repeated earthquakes on steel frames in terms of the behaviour factor $q$ and suggested that a reduction in the $q$-factor should be considered for both limit states dealing with damage control and collapse, as well as an increase in the damage index to account for the impact of multiple earthquakes. Li and Ellingwood (2007) performed damage assessment on a two-storey steel frame and found that the amplitude and frequency content of aftershocks had a significant effect on the damage pattern induced by aftershocks. Loulelis et al. (2012) examined the seismic behaviour of a planar steel moment frame and demonstrated that earthquake sequences tended to cause more severe damage on structures and higher displacement and ductility demands. Li et al. (2014) performed fragility assessment on steel frames under mainshock-aftershock (MS-AS) sequences and argued that steel frames were likely to collapse even during a small aftershock if the mainshock had a high intensity. More recently, Ruiz-García et al. (2018) pointed out the necessity of using a 3D-model of steel frame other than 2D-model in assessment, since the behaviour of 3D-model and its corresponding 2D-model may differ significantly. They also emphasised the importance of using bi-directional earthquake inputs, especially in the case when the torsion of columns or the overall structure is of relevance.

Despite many previous research on the seismic performance of steel moment frames under sequential earthquakes, very limited studies have been conducted to include the effects of masonry infill walls. The presence of masonry infill is able to considerably alter the seismic behaviour of bare steel frames, including the increase in initial stiffness, ultimate strength and the ability of dissipating energy under earthquake loading. Masonry infill 
may also have negative effects on the steel frame, such as high local demand at connections due to its strut action and the soft storey mechanism. In recent decades, many research have been carried out on the seismic behaviour of steel frames with masonry infill (e.g., Ghazimahalleh 2007; Tasnimi and Mohebkhah 2011; Markulak et al. 2013; Najarkolaie et al. 2017). Meanwhile, numerous previous studies have also developed simplified strut models for masonry infill walls, which include single-strut model (e.g., Fardis and Panagiotakos 1997; Dolšek and Fajfar 2008; Liberatore and Decanini 2011) and multi-strut model (e.g., El-Dakhakhni et al. 2003; Yekrangnia and Mohammadi 2017). The development of strut models has allowed easier modelling of infilled structures in finite element software at a low cost of computational demand.

To fill the gap, studies should be carried out on the seismic performance of infilled steel frames under earthquake sequences, especially focusing on the structural performance during aftershocks. State-dependent fragility analysis is a common approach within the framework of performance-based earthquake engineering to determine the vulnerability of structures to aftershocks considering its damage state after a strong ground motion. A few relevant analysis frameworks have already been proposed in previous studies, which were based on incremental dynamic analysis (IDA) (Vamvatsikos and Cornell 2002). For example, Li et al. (2014) and Ruiz-García and Aguilar (2015) scaled each mainshock in a way that a building reaches the target residual or transient interstorey drift after the scaled mainshocks, and then performed IDA on the damaged building under aftershocks up to collapse. In such a manner the effects of aftershocks on buildings with different levels of mainshock-induced damage can be investigated. Furtado et al. (2018) adopted a similar approach in their study, however, instead of scaling the mainshocks, they applied the unscaled mainshocks to a framed structure and divided the results into several groups based on the damage level reached after each mainshock. Besides, they also avoided scaling up the aftershocks to an unrealistic level by putting an upper bound on the scaling of aftershocks such that their PGA did not exceed the PGA of corresponding mainshocks.

This paper presents the seismic fragility assessment of existing steel moment frames with masonry infills subjected to MS-AS earthquake sequences. The assessment framework will be introduced at the beginning and will be illustrated by assessing a case study steel moment frame. The steel frame is a three-storey non-seismically designed residential building, which is a representative of typical residential steel buildings in Southern Europe. The assessment framework includes two part of analysis. The first part of analysis includes fragility analysis of the steel frame with an undamaged initial condition subjected to mainshocks and MS-AS sequences. The second part of analysis contains aftershock fragility assessment of the steel frame assuming different levels of post-mainshock damage on the structure. State-dependent aftershock fragility curves will then be derived, which is aimed at assessing the influence of post-mainshock damage on the vulnerability of the steel frame subjected to aftershocks.

\section{Methodology}

The framework adopted in the present paper consists of two parts of fragility assessment of a case study steel moment frames with masonry infill. In the first part, fragility assessment of the undamaged steel frame is demonstrated, in which the fragility curves are derived through standard procedure of IDA (Vamvatsikos and Cornell 2002). In the second part, an improved aftershock assessment framework is presented, which utilises the state-dependent 
aftershock fragility curves to assess the resistance of steel moment frames with post-mainshock damage. In both parts, the presence of masonry infill will be accounted for during the numerical analysis.

\subsection{Fragility assessment of undamaged structures}

This first part of analysis is aimed at presenting the conventional fragility assessment of steel moment frames, where the IDA is performed on undamaged structures subjected to records of mainshocks and MS-AS sequences, respectively. It should be noted that in this part of analysis each record of MS-AS sequence is considered as a single ground motion record, which means the mainshock and aftershock are incrementally scaled by the same factor up to the collapse of structures. Fragility curves are then derived for the steel moment frame at each pre-defined limit states. Lastly, comparisons are made between the fragility curves obtained for the case of mainshocks and MS-AS sequences.

\subsection{Aftershock fragility assessment of damaged structures}

The analysis framework adopted in this part is considered an extension to the approach presented by Li et al. (2014), which is aimed at estimating the seismic vulnerability of steel moment frames subjected to aftershocks through state-dependent fragility curves. In other words, the framework adopted here can be considered as a supplement to the conventional fragility assessment described in the previous section, which is able to provide useful information for post-mainshock assessment of a steel moment frame and allows quick decisionmaking regarding the actions to be taken, such as re-occupancy, repairing and retrofitting.

This part of analysis uses also the IDA to derive fragility curves, but the mainshocks and aftershocks are scaled independently. The procedure is shown in Fig. 1 for an existing steel moment frame, and is explained in detail as follows:

(a) Define appropriate limit states. It is better to use the same limit states in the previous part of conventional fragility assessment for consistency and standardised limit states are usually preferred. As shown in Fig. 1, three limit states are defined in the order of increasing severity, namely light damage, moderate damage and severe damage, each of which is associated with a pre-defined peak transient roof drift ratio (RDR). As a result, the RDR is also used as the engineering demand parameter (EDP) in the fragility assessment.

(b) Select a suite of MS-AS sequence records. As-recorded sequential ground motions are usually recommended, compared to repeated ground motion records or synthetic records.

(c) Select an appropriate intensity measure (IM) for implementing the IDA and deriving fragility curves. If an IM depending on the structural property is selected, e.g., the spectral acceleration, the effects of period elongation due to damage on the structure has to be correctly accounted for.

(d) Use the defined limit states as the target levels of post-mainshock damage on the steel moment frame. As shown in Fig. 1, three post-mainshock damage levels are considered, namely no damage, light and moderate damage level. It should also be noted that the severe damage level is not included here as a targe damage level, as it is usually associated with the collapse of buildings and there is no need to consider the performance of collapsed buildings in upcoming aftershocks. 

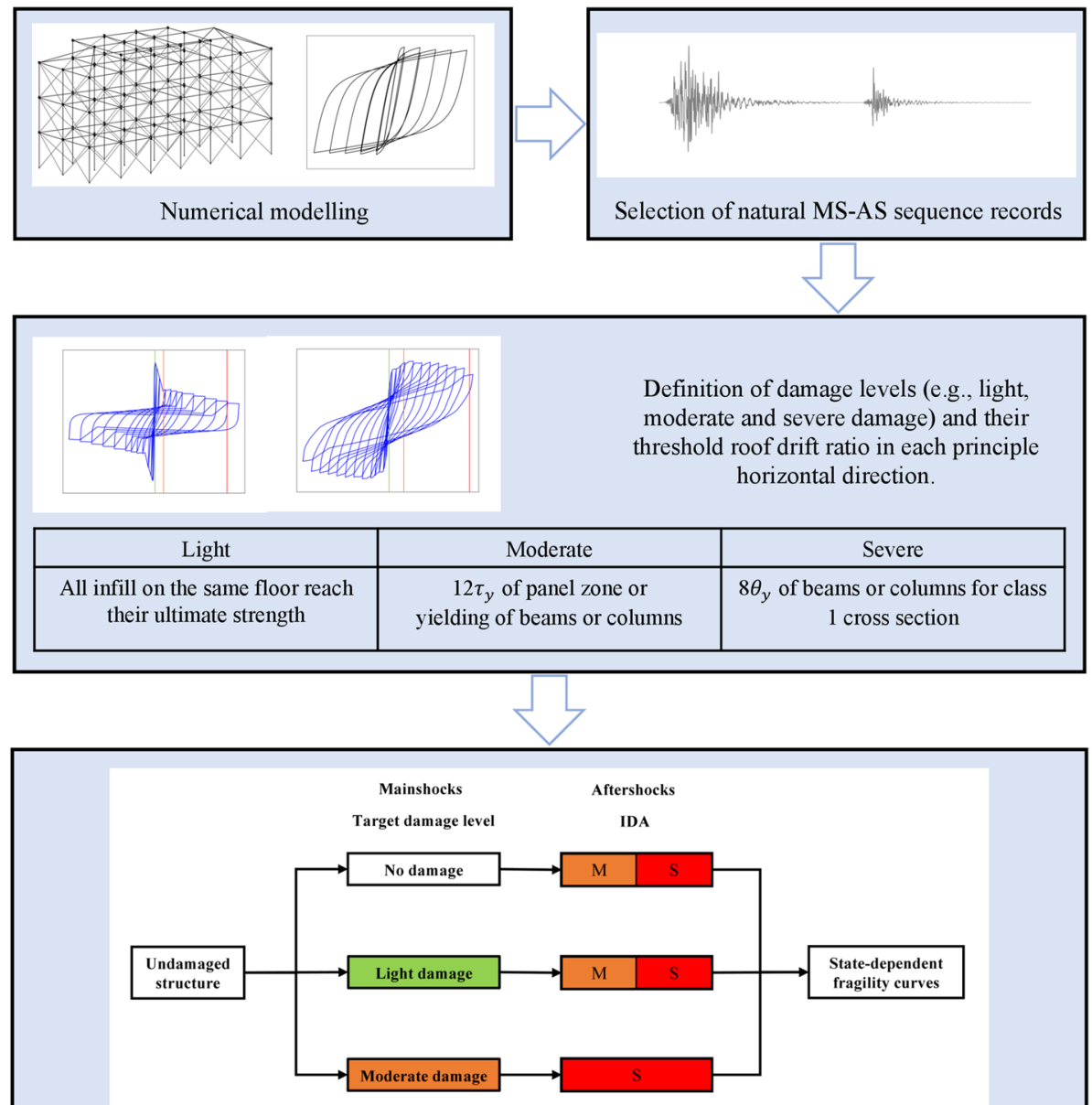

Scale each mainshock such that the structure reaches the target damage level (e.g., no damage, light and moderate damage)

Fig. 1 Analysis procedure of aftershock fragility assessment of steel frames with post-mainshock damage

(e) Individually scale the mainshock in each selected MS-AS sequence record such that the steel moment frame reaches the targe post-mainshock damage level. Then for each scaled mainshock, scale its associated aftershock independently up to the collapse of the structure. Subsequently, the state-dependent aftershock fragility curves can be derived based on the IDA.

(f) Evaluate the change of seismic resistance the steel moment frame due to post-mainshock damage by making use of appropriate characteristic values.

Three common choices of characteristic value are the 5th, 16th and 50th percentiles of probably distribution. The 5 th percentile has been adopted as the characteristic value by European codes to describe material properties, which is statistically two standard deviation away from the mean value. The 16th percentile is usually adopted as the characteristic value in seismic hazard-related studies (Bradley 2011), which is one standard deviation 
away from the mean value. Lastly, the 50th percentile is simply the mean value of normal distribution and the median of the corresponding lognormal distribution.

\section{Case study}

\subsection{Description of the case study steel moment frame and numerical modelling}

The case study building is a non-seismically designed three-storey steel moment frame located in Central Italy. The steel frame has a trapezoidal floor plan; its dimension is provided in Fig. 2a. The ground floor is $3.6 \mathrm{~m}$ in height while the first and second floors are $3.55 \mathrm{~m}$ in height. There is also a $1.8 \mathrm{~m}$-high roof floor on top of the structure, leading to a total height of $12.5 \mathrm{~m}$ of the steel building. The external and internal beams are HEA160 and HEA300, respectively, and the columns are all HEA200, whose strong axis is in the transvers direction of the structure. The steel grade used in design is S235, hence the design yield strength of structural steel is $235 \mathrm{MPa}$. However, due to the lack of information of onsite material tests, the actual yield strength of steel used in the numerical model is $215 \mathrm{MPa}$, assuming a standard deviation of $15 \mathrm{MPa}$ and a confidence factor of 1.2, according to the knowledge levels defined in EC8-3 (BSI 2005). The beams are connected to columns through full penetration welding. Finally, the masonry infilled walls consist of two
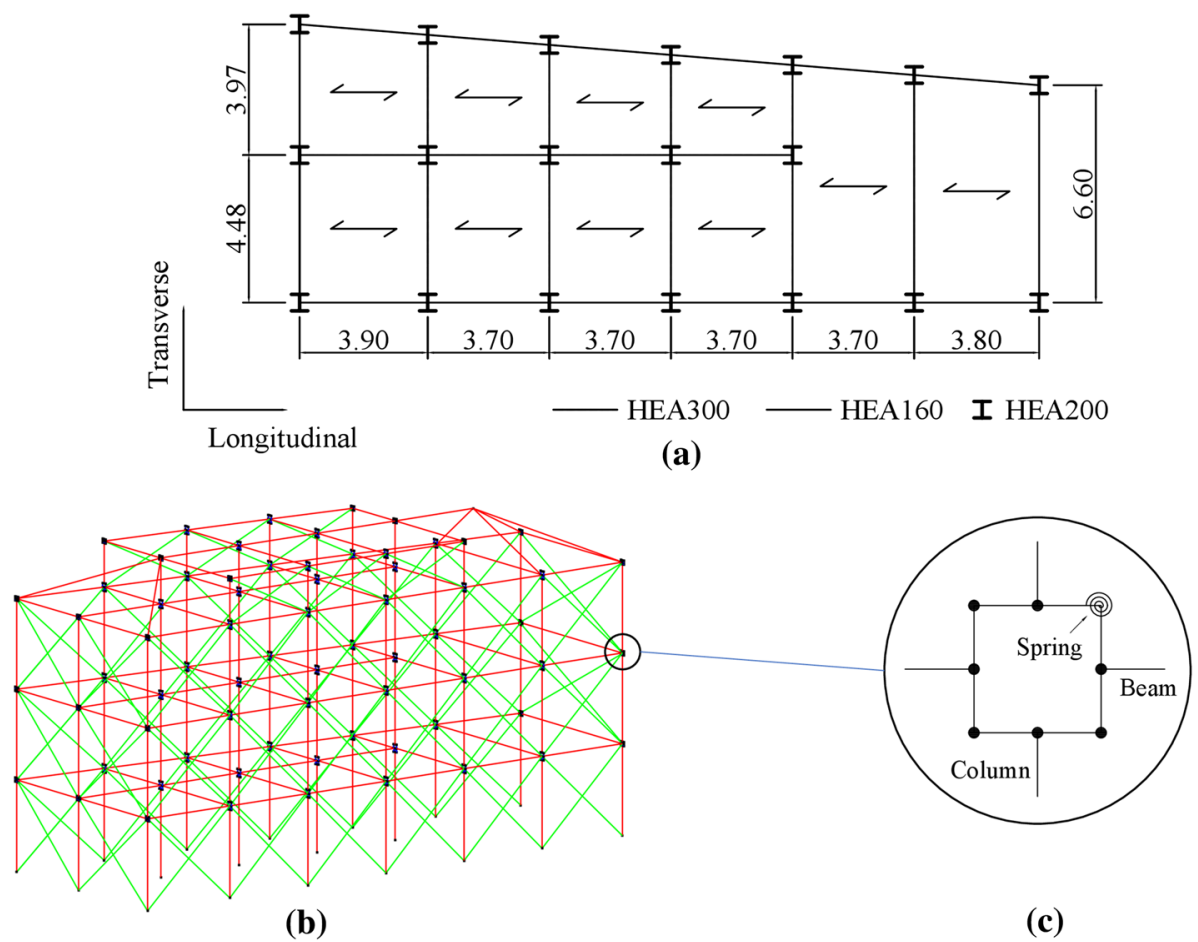

Fig. 2 Description of the case study existing steel moment frame: a layout; $\mathbf{b}$ numerical model in OpenSees (slab elements are omitted for clarity); c details of panel zones 


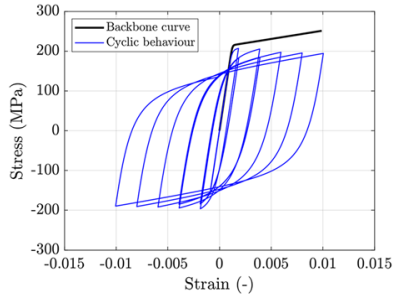

(a)

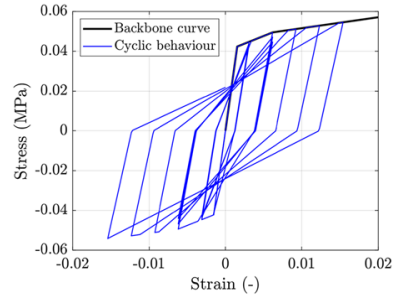

(b)

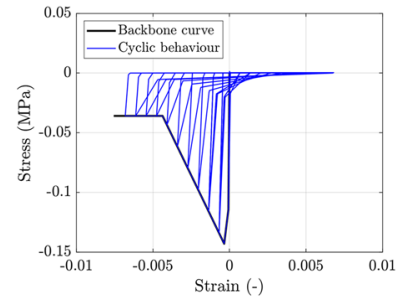

(c)

Fig. 3 Cyclic behaviour of materials: a structural steel; b panel zone spring; c masonry struts

Table 1 Natural periods (sec) of the translational mode in the longitudinal (L) and transverse (T) direction, and the rotational $(\mathrm{R})$ mode about the vertical direction (see Fig. 1)

\begin{tabular}{|c|c|c|c|c|c|c|}
\hline \multirow[t]{2}{*}{ Model } & \multicolumn{2}{|l|}{ 1st Mode } & \multicolumn{2}{|l|}{ 2nd Mode } & \multicolumn{2}{|l|}{ 3rd Mode } \\
\hline & Direction & Period & Direction & Period & Direction & Period \\
\hline Infilled Frame & $\mathrm{T}$ & 0.317 & $\mathrm{R}$ & 0.138 & $\mathrm{~L}$ & 0.105 \\
\hline
\end{tabular}

layers of perforated bricks of size $120 \times 250 \times 80 \mathrm{~mm}$. The compressive strength of bricks and mortar are assumed to be 10 and $5 \mathrm{MPa}$, respectively.

The numerical models of the steel frames were implemented in OpenSees (Mazzoni et al. 2006), as shown in Fig. 2b. Beams and columns were modelled as force-based elements with fibre sections, and the corresponding material property of structural steel was represented by the Giuffré-Menegotto-Pinto constitutive law (Filippou et al. 1983; Menegotto and Pinto 1973). The cyclic behaviour of steel is demonstrated in Fig. 3a, where the elastic modulus was assumed to be $210 \mathrm{GPa}$ and the strain hardening ratio 0.02. Apart from the beams and columns, the column panel zones were also modelled using the model developed by Gupta and Krawinkler (1999), as shown in Fig. 2c, where the rectangular shape of column panel zone was formed through small rigid elements and the shear deformation of column panel zone was controlled through a rotational spring. The property of the rotational spring is demonstrated in Fig. 3b. Additionally, masonry infill walls were modelled utilising the single-strut model due to its great simplicity and acceptable accuracy. The infill struts had the same thickness as the real infilled walls and their width was determined based on the property of infilled walls and the confining frame. The property of the masonry infill struts was represented by the multi-linear curve developed by Fardis and Panagiotakos (1997), which is demonstrated in Fig. 3c. Finally, the slab was simplified as two rigid struts placed diagonally in each column grid across the entire floor area.

Table 1 shows the natural periods of the infilled steel moment frame obtained from modal analysis. The first mode was found to be a translational mode in the transverse direction with a period of $0.317 \mathrm{~s}$, the second mode to be a rotational mode with a period of $0.138 \mathrm{~s}$ and the third mode to be a translational mode in the longitudinal direction with a period of $0.105 \mathrm{~s}$. The results of modal analysis suggested that appropriate actions should be taken to account for the torsional effects due to the trapezoidal floor plan. To this end, the storey mass was assigned to each floor node based on their tributary area, instead of using lumped mass at the centre of mass of each storey. The mass of masonry infill was also included in the model for both of the bare and infilled frame, and was assigned to each perimeter node accordingly. In addition, the 
torsional effects were also accounted for during the definition of limit states, which are presented in the following section.

\subsection{Definition of limit states and targe post-mainshock damage level}

The drift ratio at centre of mass of top floor, referred to as roof drift ratio hereafter, was adopted as the engineering demand parameter (EDP) in this study, as it was considered a convenient parameter to be monitored during IDA. Many relevant limit states have been proposed in literature for steel buildings, such as ASCE41-06 (ASCE 2005), Rossetto and Elnashai (2005) and Ghobarah (2004), however, a set of roof drift limits were determined specifically for the case study steel moment frame based on the results of cyclic pushover analysis. The threshold values were determined by conducting safety checks at local component level during the cyclic pushover analysis, hence was capable of representing the damage developed in the steel frame. Besides, the safety checks at local component level also to some extent allowed the roof drift limits to account for the torsional effects due to the irregular plan layout of the steel frame, which could cause larger drift demand at locations other than the centre of mass. Lastly, by conducting cyclic pushover analysis, the stiffness degradation and strength deterioration could be taken into consideration when formulating the roof drift limits.

Three limit states were defined for the case study building, namely light damage, moderate damage and severe damage, which are described as follows:

- Light damage Infill walls on the same storey reaching their ultimate strength capacity; no yielding on structural steel components;

- Moderate damage First yielding of beams and columns, or first panel zone twelve times the yielding deformation according to ASCE41-17 (ASCE 2017);

- Severe damage First beam or column reaching eight times its yielding rotation according to EC8-3 (BSI 2005), which is usually associated with the collapse of existing buildings.

Based on the above description of limit states, the roof drift limits were determined and summarised in Table 2. Illustration of the roof drift limits are also presented in Fig. 4, together with the pushover curves in the longitudinal and transverse direction. The pushover was done utilising modal lateral pattern according to EC8-3 (BSI, 2005), which was dependent on the first mode shape in the corresponding direction and the mass assigned to each node. The cyclic pushover involved initially two cycles within the elastic range and then three cycles at the increment of yielding displacement, followed by cycles at the increment of twice the yielding displacement up to the severe damage level was achieved. The steel frame was considered to have reached one limit state upon the onset of that limit state in either the longitudinal or the transverse direction.

After the definition of limit states, the target post-mainshock damage level could be decided accordingly. In this case study, three target post-mainshock damage levels were considered, which were no damage, light and moderate damage level. Here no damage means an undamaged initial condition of the steel frame, which was for easy control achieved by not

Table 2 Roof drift ratio (\%) limits determined for the case study steel frames

\begin{tabular}{llll}
\hline Damage level & Light & Moderate & Severe \\
\hline Longitudinal & 0.04 & 0.32 & 2.41 \\
Transverse & 0.06 & 0.70 & 3.60 \\
\hline
\end{tabular}




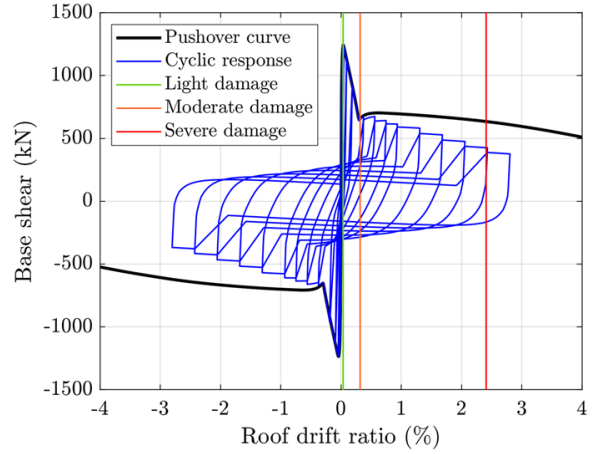

(a)

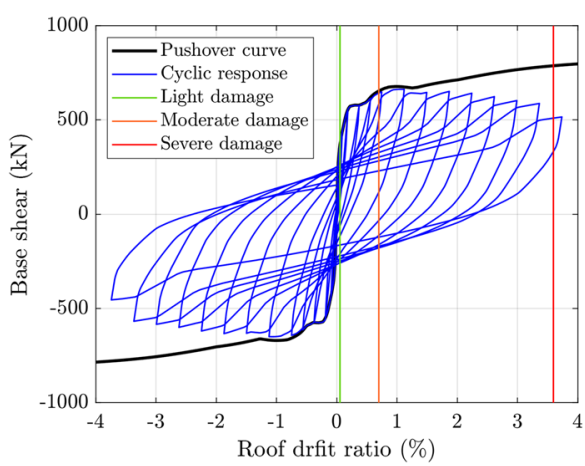

(b)

Fig. 4 Cyclic pushover curves: a longitudinal direction; $\mathbf{b}$ transverse direction

applying the mainshock records. Besides, light and moderate post-mainshock damage level were considered coincident with the light damage and moderate damage limit state. Lastly, as mentioned before the severe damage level was not included here as a targe damage level, as it was usually associated with the collapse of buildings and there was no need to consider the performance of collapsed buildings in upcoming aftershocks.

\subsection{Selection of mainshock-aftershock ground motion records}

A set of 20 records of earthquake sequences were selected from worldwide ground motion databases, including PEER-NGA (Seyhan et al. 2014), ITACA (Luzi et al. 2019) and K-NET (NIED 2019), to be employed in the finite element model. Each earthquake sequence comprised two events, i.e. a mainshock and an aftershock. The selection of earthquake sequence records was aimed at mainshock with magnitude higher than 5.5 with one major aftershock, whose PGA is not less than $20 \%$ of the PGA of its associated mainshock. To simulate the time period between the mainshock and its aftershock, an accelerogram with zero-amplitude was also added to each MS-AS sequence record between the mainshock and aftershock, which allowed the free vibration of the steel frame to drop to a small amplitude before being subjected to the aftershock. Bidirectional ground motions were considered in this study, where the two horizontal components of selected ground motion records were applied to the steel frame simultaneously.

Table 3 contains a summary of the information of the selected earthquake records and Fig. 5 shows the distribution of the spectral acceleration at the fundamental period $\mathrm{S}_{\mathrm{a}}\left(\mathrm{T}_{1}\right)$ and cumulative absolute velocity (CAV) of the selected earthquake records, all of which were considered as the potential IMs for aftershock fragility assessment in this study. The PGA reported in Table 3 is defined as the PGA of bidirectional ground motions, which is taken as the square root of the sum of the squares (SRSS) of the PGA of its two components. The same method also applies to the definition of $S_{a}\left(T_{1}\right)$. Besides, the CAV is defined as the integral of the absolute value of the acceleration time history of an earthquake and is expressed by the following equation (Campbell and Bozorgnia 2010; O'Hara and Jacobson 1991):

$$
C A V=\int_{0}^{t_{\max }}|a(t)| d t
$$


Table 3 Summary of the selected $20 \mathrm{MS}$-AS earthquake sequence records $\left(\lambda=\mathrm{PGA}_{\mathrm{AS}} / \mathrm{PGA}_{\mathrm{MS}}\right)$

\begin{tabular}{|c|c|c|c|c|c|c|c|}
\hline \multirow[t]{2}{*}{ Event name } & \multicolumn{2}{|c|}{ PGA (g) } & \multirow[t]{2}{*}{$\lambda$} & \multirow[t]{2}{*}{ Event name } & \multicolumn{2}{|c|}{ PGA (g) } & \multirow[t]{2}{*}{$\lambda$} \\
\hline & MS & AS & & & MS & AS & \\
\hline Armenia Spitak & 0.27 & 0.09 & 0.33 & Japan Fukushima & 0.58 & 0.19 & 0.33 \\
\hline Chile Valparaiso & 0.79 & 0.27 & 0.34 & Japan Niigata & 0.68 & 0.76 & 1.12 \\
\hline China Northwest & 0.36 & 0.19 & 0.53 & New Zealand Christchurch & 0.29 & 0.23 & 0.81 \\
\hline Greece Kalamata & 0.29 & 0.31 & 1.08 & New Zealand Edgecumbe & 0.60 & 0.13 & 0.22 \\
\hline India Chamoli & 0.42 & 0.08 & 0.19 & New Zealand Weber & 0.24 & 0.32 & 1.33 \\
\hline Iran Varzaghan & 0.57 & 0.75 & 1.30 & Taiwan Chi-Chi & 1.32 & 0.52 & 0.39 \\
\hline Italy Emilia & 0.37 & 0.37 & 0.99 & Turkey Duzce & 0.42 & 0.27 & 0.63 \\
\hline Italy Friuli & 0.46 & 0.14 & 0.31 & USA Chalfant & 0.60 & 0.36 & 0.60 \\
\hline Italy Irpinia & 0.43 & 0.10 & 0.24 & USA Mammoth & 0.61 & 0.25 & 0.40 \\
\hline Italy NoceraUmbra & 0.74 & 0.61 & 0.82 & USA Whittier & 0.48 & 0.28 & 0.58 \\
\hline
\end{tabular}

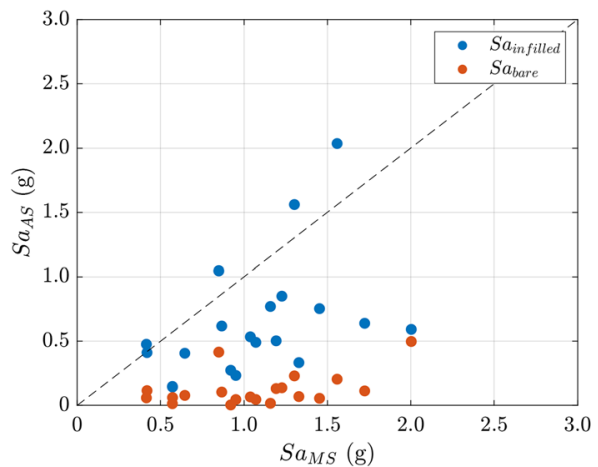

(a)

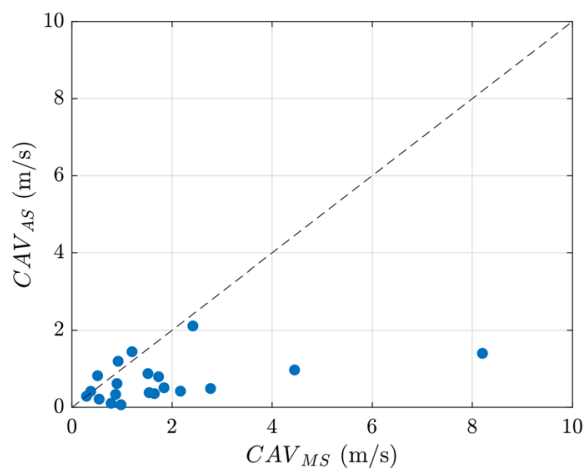

(b)

Fig. 5 Distribution of $\mathbf{a}$ the spectral acceleration $\mathrm{Sa}\left(\mathrm{T}_{1}\right)$ and $\mathbf{b}$ the cumulative absolute velocity CAV of the selected earthquake records

where $t_{\max }$ is the duration of the earthquake and $a(t)$ is the time history of the acceleration of earthquakes.

It can be concluded from Table 3 that for most of the selected records, the aftershocks have smaller PGA than their corresponding mainshocks. The lowest and highest ratio of aftershock PGA to mainshock PGA is 0.19 and 1.33, respectively. Figure 5a shows the distribution of aftershock $S_{a}\left(T_{1}\right)$ with respect to mainshock $S_{a}\left(T_{1}\right)$. The aftershock $S_{a}\left(T_{1}\right)$ was extracted from 5\%-damping response spectra for both the bare frame and the infilled frame, while the mainshock $S_{a}\left(T_{1}\right)$ was obtained for the infilled frame only. The aftershock $\mathrm{S}_{\mathrm{a}}\left(\mathrm{T}_{1}\right)$ of the bare frame is involved so that the effect of period elongation can be observed. It is shown in Fig. 5a that similar to the case of PGA, the aftershock $\mathrm{S}_{\mathrm{a}}\left(\mathrm{T}_{1}\right)$ tends to be lower than their associated mainshock $\mathrm{S}_{\mathrm{a}}\left(\mathrm{T}_{1}\right)$ with a few exceptions. When the damage on the infill walls are considered, the natural period of the steel frame shifts from short period corresponding to its infilled configuration to long period corresponding to its bare configuration, which leads to lower aftershock $\mathrm{S}_{\mathrm{a}}\left(\mathrm{T}_{1}\right)$. On the other hand, Fig. $5 \mathrm{~b}$ shows the 


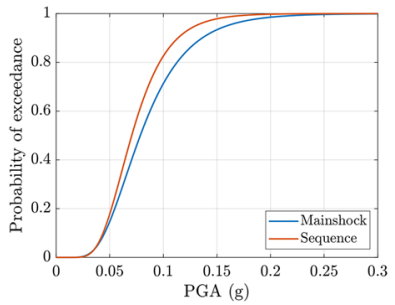

(a)

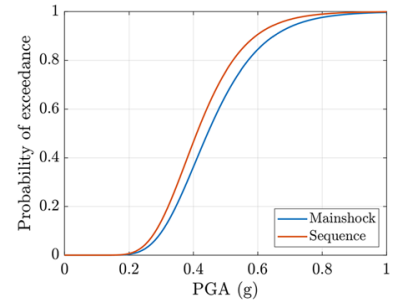

(b)

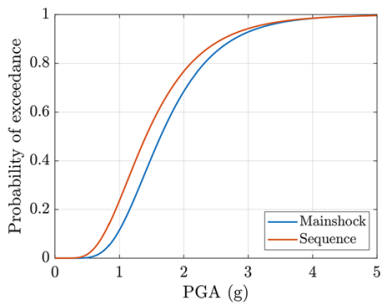

(c)

Fig. 6 Fragility curves of undamaged steel frame: a light damage; b moderate damage; $\mathbf{c}$ severe damage

Table 4 Median $(\mu)$ and standard deviation $(\beta)$ of the fragility curves in Fig. 7 (unit: g)

\begin{tabular}{|c|c|c|c|c|c|c|}
\hline & \multicolumn{2}{|c|}{ Light damage } & \multicolumn{2}{|c|}{$\begin{array}{l}\text { Moderate } \\
\text { damage }\end{array}$} & \multicolumn{2}{|c|}{$\begin{array}{l}\text { Severe dam- } \\
\text { age }\end{array}$} \\
\hline & $\mu$ & $\beta$ & $\mu$ & $\beta$ & $\mu$ & $\beta$ \\
\hline Mainshock & 0.079 & 0.431 & 0.444 & 0.297 & 1.639 & 0.413 \\
\hline MS-AS Sequence & 0.071 & 0.373 & 0.410 & 0.289 & 1.410 & 0.480 \\
\hline$\mu_{S e q} / \mu_{M S}$ & 0.899 & & 0.923 & & 0.860 & \\
\hline
\end{tabular}

distribution of aftershock CAV with respect to the mainshock CAV. This IM is independent of structural property, so there is no need to account for the effects of period elongation. Similar to the case of PGA and $\mathrm{S}_{\mathrm{a}}\left(\mathrm{T}_{1}\right)$, the aftershock CAV is in general smaller than the mainshock $\mathrm{CAV}$ except for those cases with very strong aftershocks.

\section{Fragility analysis of the undamaged building}

This section presents the results of conventional fragility assessment performed on the case study steel moment frames, where the performance of undamaged steel frame subjected to records of mainshocks and MS-AS sequences was evaluated. The methodology described in Sect. 2.1 was adopted for this part of assessment.

The fragility curves are presented in Fig. 6. It is noticed that MS-AS sequences tended to cause slightly more significant damage on the steel moment frame than the single earthquakes. Table 4 summarised the median and standard deviation of each distributions presented in Fig. 6. It is demonstrated that when the steel frame was subjected to mainshocks only, the medians of PGA were $0.079,0.444$ and $1.639 \mathrm{~g}$ respectively for light, moderate and severe damage limit state. On the other hand, when the steel frame was subjected to MS-AS sequences, the medians of PGA were $0.071,0.410$ and $1.410 \mathrm{~g}$ respectively for the three limit states, which were approximately $10 \%$ lower than the medians obtained in the case of single earthquakes.

Figure 7 a shows the variation of increment of probability of exceeding a limit state due to the aftershocks against PGA, which is denoted by the difference between the two fragility curves in each subplot of Fig. 6 . The positions of the two corresponding medians are also indicated in Fig. 7. It is noticed that in the case of light damage, as shown in Fig. 8a, the aftershocks presented pronounced effects at high PGA values relative to the medians. However, the peak tended to shift to relatively low PGA values with 


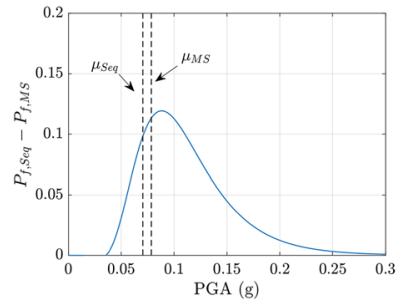

(a)

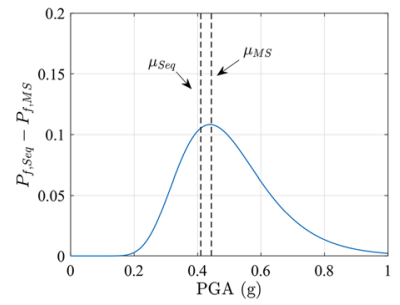

(b)

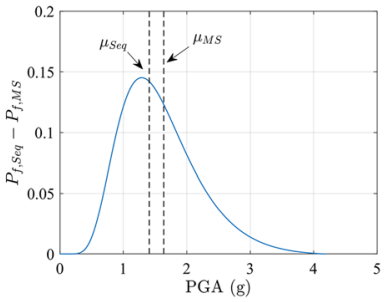

(c)

Fig. 7 Increase of probability of exceeding different limit states due to aftershocks: a light damage; b moderate damage; c severe damage

superior limit states, as demonstrated in Fig. 8b and c, which suggesting that the aftershocks began to cause the failure of the steel frame at earlier stages. This phenomenon was due to the fact that at light damage limit state, most of the selected aftershocks had a PGA that was too small to cause any damage on the steel frame when the PGA of the sequence were smaller than the median. However, at superior limit states, the aftershocks tended to have a PGA that was large enough to cause significant damage on the steel frame even when the PGA of sequences were smaller than the medians. This suggested that if the median, or the more conservative 5th and 16th percentile, of PGA was adopted as the characteristic value, the influence of aftershocks was more essential at superior limit states.

The results obtained from the above conventional fragility assessment were able to draw very general conclusions on the seismic vulnerability of the case study steel frame considering the effects of sequential earthquakes, which could be helpful when predicting the overall performance of existing steel frames subjected to future earthquake events. However, it provided no clear indication on the intensity of aftershocks associated with progression of limit states, hence its contribution to post-mainshock assessment of the steel frame was limited. To this end, it is necessary to perform further fragility assessment on the steel frame using state-dependent fragility curves, where the mainshocks and aftershocks are scaled separately and the influence of damage caused by mainshocks on the steel frame are also taken into consideration.
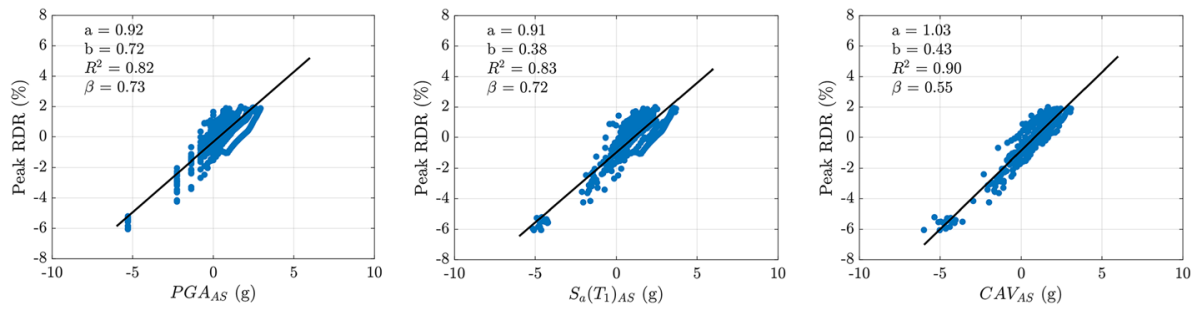

Fig. 8 Regression analyses for different aftershock IMs with no post-mainshock damage 


\section{Performance of the mainshock-damaged case study building}

\subsection{Evaluation of aftershock IMs with post-mainshock damage}

Before the fragility assessment of the infilled steel frame, three IMs of aftershocks were evaluated to find the optimal IM for seismic assessment of the case study steel moment frame with post-mainshock damage caused by mainshocks. The roof drift limits reported in Table 2 were implemented here to describe the target level of post-mainshock damage on the steel frame. Consequently, the RDR of the infilled steel frame during the aftershocks, noted as $\mathrm{RDR}_{A S}$ was used as EDP for this part of analysis. The subscript $A S$ was also added to the IMs adopted in the following analysis to indicate that they represented the intensity of aftershocks.

A linear model was adopted to describe the relationship between the natural logarithm of IM and the natural logarithm of EDP, which is expressed by the following equation:

$$
\ln (E D P)=a \ln (I M)+\ln (b)
$$

where $\mathrm{a}$ and $\mathrm{b}$ are coefficients defined by the regression analysis. The dispersion is estimated via the conditional standard deviation of the regression $\beta_{\mathrm{EDPIIM}}$, which is expressed as follow:

$$
\beta_{E D P \mid I M}=\sqrt{\frac{\sum\left(\ln \left(E D P_{i}\right)-\ln \left(b I M^{a}\right)\right)^{2}}{N-2}}
$$

Since it is generally not possible to accurately account for all earthquake characteristics, such as magnitude, frequency content and energy, through one single parameter, it is then of great importance to find the optimal IM for fragility assessment (Baker and Cornell 2005). In this study, the efficiency, practicality and proficiency of three IMs were evaluated: PGA, $\mathrm{S}_{\mathrm{a}}\left(\mathrm{T}_{1}\right)$ and CAV of aftershocks. Sufficiency and hazard computability were not included in the evaluation of IM. The former required the knowledge of seismic characteristics of aftershocks, such as the magnitude and epicentre, which was not always available in the database. The latter was related to the hazard information available of the region of the case study building, hence was believed to be less essential in this study.

The IMs considered were $\mathrm{PGA}_{A S}, \mathrm{~S}_{\mathrm{a}}\left(\mathrm{T}_{1}\right)_{A S}$ and $\mathrm{CAV}_{A S}$. PGA is considered the simplest and most explicit measure of earthquakes, as it is independent of structural properties and can be directly obtained from the accelerogram of ground motions. $\mathrm{S}_{\mathrm{a}}\left(\mathrm{T}_{1}\right)$ is another popular IM of earthquakes, which on the contrary depends significantly on structural properties, hence is often more accurate than PGA in the case of estimating seismic action induced on a specified structure. However, the use of $S_{a}\left(T_{1}\right)$ can be more complex in the case of aftershock fragility analysis due to the period elongation of structures, hence its value needs to be updated for every single damaged state of the steel frame. CAV is associated with the amplitude and duration of earthquake acceleration time history; therefore, it is more capable of capturing the characteristics of aftershocks, which tend to have less cycles with large amplitudes, hence lower values of CAV than mainshocks. The results of regression analysis for no damage, light damage and moderate damage were summarised in Figs. 8, 9, 10.

Efficiency: Efficiency is one of the major essential measure of IMs. An efficient IM should lead to reduced variation about the estimated seismic demand EDP (Shome and Cornell 1998; Luco and Cornell 2007), hence the lower the dispersion $\beta_{\text {EDPIIM }}$, the more efficient the IM. Table 4 contains a comparison of the efficiency of IMs. It can 

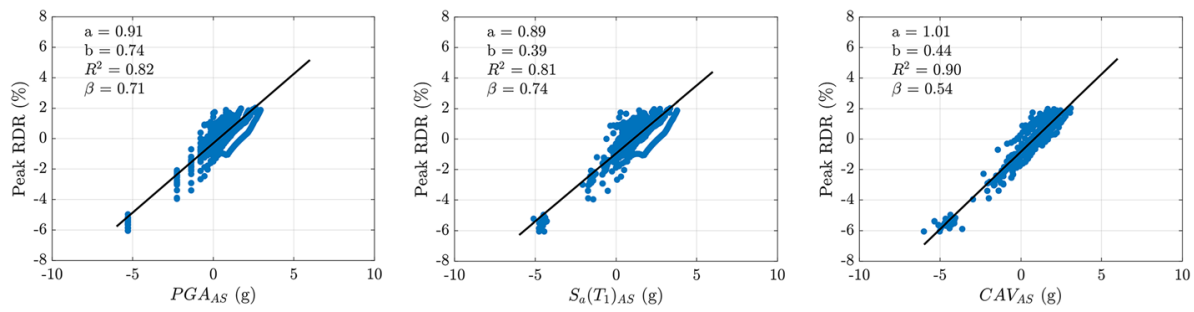

Fig. 9 Regression analyses for different aftershock IMs with light post-mainshock damage

be concluded that for all the three levels of post-mainshock damage on the steel frame, $\mathrm{CAV}_{A S}$ was evidently more efficient than $\mathrm{PGA}_{A S}$ and $\mathrm{S}_{\mathrm{a}}\left(\mathrm{T}_{1}\right)_{A S}$, which were characterised by similar values of dispersion. It is also noticed that the dispersion obtained by using the three IM candidates remained approximately constant with the increasing level of post-mainshock damage, despite that the PGA showed a slight trend of being more efficient.

Practicality: Practicality is a measure that describes the correlation between IM and EDP. A practical IM means there is strong correlation between the level of IM and the level of structural response EDP, and vice versa. The practicality of IM is quantitatively represented by the coefficient $a$ of the line of best fit, where a larger value of $a$ indicates a more practical IM. Table 5 summaries the values of coefficient $a$ from all regression. It is found that $\mathrm{CAV}_{A S}$ was constantly more practical than $\mathrm{PGA}_{A S}$ and $\mathrm{S}_{\mathrm{a}}\left(\mathrm{T}_{1}\right)_{A S}$, but not by a large margin. It is also noticed that $\mathrm{PGA}_{A S}$ and $\mathrm{S}_{\mathrm{a}}\left(\mathrm{T}_{1}\right)_{A S}$ showed very similar practicality, which was the same as the case of efficiency. Lastly, the practicality of all three IMs tended to decrease with increasing level of post-mainshock damage, which dropped significantly by about $40 \%$ when the post-mainshock damage was at the moderate damage level. This was due to that, as shown in Fig. 10, the distribution of dots showed a two-segmented relationship between the IM and the EDP, which had a smaller slope at small IMs. This behaviour

Table 5 Comparison of dispersion $\beta_{\text {EDPIIM }}$ to evaluate efficiency of IMs

\begin{tabular}{llll}
\hline MS-damage & $\mathrm{PGA}_{\mathrm{AS}}$ & $\mathrm{S}_{\mathrm{a}}\left(\mathrm{T}_{1}\right)_{\mathrm{AS}}$ & $\mathrm{CAV}_{\mathrm{AS}}$ \\
\hline No damage & 0.73 & 0.72 & $\mathbf{0 . 5 5}$ \\
Light damage & 0.71 & 0.74 & $\mathbf{0 . 5 4}$ \\
Moderate damage & 0.70 & 0.72 & $\mathbf{0 . 5 7}$ \\
\hline
\end{tabular}

The bold values are simply to indicate the best intensity measure in terms of a certain aspect (efficiency, proficiency and practicality)

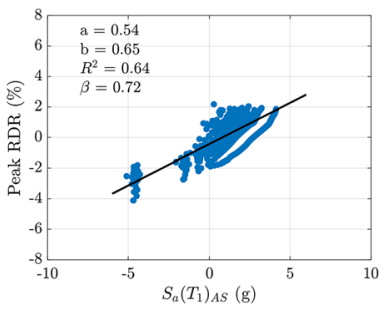

Fig. 10 Regression analyses for different aftershock IMs with moderate post-mainshock damage 
Table 6 Comparison of coefficient $a$ to evaluate practicality of IMs

\begin{tabular}{llll}
\hline MS-damage & $\mathrm{PGA}_{\mathrm{AS}}$ & $\mathrm{S}_{\mathrm{a}}\left(\mathrm{T}_{1}\right)_{\mathrm{AS}}$ & $\mathrm{CAV}_{\mathrm{AS}}$ \\
\hline No damage & 0.92 & 0.91 & $\mathbf{1 . 0 3}$ \\
Light damage & 0.91 & 0.89 & $\mathbf{1 . 0 1}$ \\
Moderate damage & 0.55 & 0.54 & $\mathbf{0 . 6 5}$ \\
\hline
\end{tabular}

The bold values are simply to indicate the best intensity measure in terms of a certain aspect (efficiency, proficiency and practicality)

The bold values are simply to indicate the best intensity measure in terms of a certain aspect (efficiency, proficiency and practicality)

\begin{tabular}{llll}
\hline MS-damage & $\mathrm{PGA}_{\mathrm{AS}}$ & $\mathrm{S}_{\mathrm{a}}\left(\mathrm{T}_{1}\right)_{\mathrm{AS}}$ & $\mathrm{CAV}_{\mathrm{AS}}$ \\
\hline No damage & 0.79 & 0.79 & $\mathbf{0 . 5 3}$ \\
Light damage & 0.78 & 0.83 & $\mathbf{0 . 5 3}$ \\
Moderate damage & 1.27 & 1.33 & $\mathbf{0 . 8 8}$ \\
\hline
\end{tabular}

Table 7 Comparison of modified dispersion $\zeta$ to evaluate proficiency of IMs

was attributed to the non-negligible post-mainshock permanent displacement of the steel frame, which led to a larger peak RDR at the first run of IDA.

Proficiency: Proficiency is a composite measure that accounts for combined effect of efficiency and practicality of IM. A metric for assessing the proficiency of IM is proposed by Padgett and Nielson (2008), which is in terms of a modified dispersion $\zeta$ as follows:

$$
\zeta=\frac{\beta_{E D P \mid I M}}{a}
$$

The use of proficiency can overcome the problem of inappropriate selection of IM based solely on the efficiency or practicality of IM. Similar to the efficiency of IM, a proficient IM is associated with a low value of modified dispersion. Tables 6, 7 shows the comparison of the modified dispersion obtained from regression analysis. It is clearly shown that $\mathrm{CAV}_{A S}$ shows a higher proficiency over $\mathrm{PGA}_{A S}$ and $\mathrm{S}_{\mathrm{a}}\left(\mathrm{T}_{1}\right)_{A S}$, regardless of the level of post-mainshock damage on the steel frame. It is also demonstrated that with the increased severity of post-mainshock damage, there was a clear reduction in the proficiency of all three IMs. In this case, the change of modified dispersion confirms the reduced adequacy of the three IMs at high level of post-mainshock damage. Finally, $\mathrm{PGA}_{A S}$ and $\mathrm{S}_{\mathrm{a}}\left(\mathrm{T}_{1}\right)_{A S}$ again exhibited similar proficiency no matter what the level of post-mainshock damage was.

To conclude, $\mathrm{CAV}_{A S}$ was in general a better IM than PGA $_{A S}$ and $\mathrm{CAV}_{A S}$ in terms of all three aspects that have been evaluated: efficiency, practicality and proficiency. Another important point was that the IMs considered in this study all exhibit reducing adequacy with the increasing level of post-mainshock damage on the case study steel frame. Future studies should be carried out to address this issue.

\subsection{Aftershock fragility curves of infilled steel frame with post-mainshock damage}

This section presents the results of fragility assessment on the damaged case study steel frame during aftershocks, which adopted the method described in Sect. 2.2. The 
main purpose of the assessment is to provide an insight of how different levels of postmainshock damage affect the seismic resistance of existing steel moment frames, and to allow quick estimate of potential structural performance during aftershocks. The fragility curves were presented in Figs. 11, 12, 13. It should be noted that instead of presenting the entire distribution, i.e. from 0 to $100 \%$ probability, the fragility curves presented were within the aftershock IM ranges of practical interest, which were determined based on the intensity of the selected as-recorded aftershocks. Besides, in order to quantify the change of structural resistance to aftershocks due to post-mainshock damage, the 5th, 16th and 50th percentiles of all three IMs were also summarised in Tables 8, 9, 10 and compared with each other in Figs. 11, 12, 13. The 5th, 16th and 50th percentiles are denoted by adding a subscript to each $\mathrm{IM}$, such as $\mathrm{PGA}_{5}, \mathrm{PGA}_{16}$ and $\mathrm{PGA}_{50}$ respectively represent the 5th, 16th and 50th percentile PGA.

Figures 11 and 12 show the fragility curves of the case study steel frame with light post-mainshock damage respectively at the moderate and severe damage limit state compared to the performance of undamaged steel frame subjected directly to aftershocks. It is shown that in general the light post-mainshock damage had slight influence on the steel frame's capacity of resisting aftershocks. The variation of all the considered percentile $\mathrm{PGA}_{A S}$ and $\mathrm{CAV}_{A S}$ were within $2 \%$ at both the moderate and severe damage limit states, while the use of $\mathrm{S}_{\mathrm{a}}\left(\mathrm{T}_{1}\right)_{A S}$ indicated a larger margin between the fragility curves of damaged and undamaged steel frame, where around 7 and $4 \%$ reduction of $\mathrm{S}_{\mathrm{a}}\left(\mathrm{T}_{1}\right)_{5}$ were observed at the moderate and severe damage limit states. Since the lightly

Table 8 Summary of the 5 th percentile as characteristic value

\begin{tabular}{|c|c|c|c|c|c|c|}
\hline \multirow[t]{2}{*}{ Post-mainshock damage } & \multicolumn{3}{|c|}{ Moderate damage level } & \multicolumn{3}{|c|}{ Severe damage level } \\
\hline & $\mathrm{PGA}_{5}$ & $\mathrm{~S}_{\mathrm{a}}\left(\mathrm{T}_{1}\right)_{5}$ & $\mathrm{CAV}_{5}$ & $\mathrm{PGA}_{5}$ & $\mathrm{~S}_{\mathrm{a}}\left(\mathrm{T}_{1}\right)_{5}$ & $\mathrm{CAV}_{5}$ \\
\hline No damage & 0.275 & 0.522 & 0.536 & 0.653 & 1.191 & 1.754 \\
\hline Light damage & 0.273 & 0.486 & 0.526 & 0.654 & 1.146 & 1.756 \\
\hline Moderate damage & N/A & N/A & N/A & 0.607 & 1.078 & 1.726 \\
\hline
\end{tabular}

Table 9 Summary of the 16th percentile as characteristic value

\begin{tabular}{|c|c|c|c|c|c|c|}
\hline \multirow[t]{2}{*}{ Post-mainshock damage } & \multicolumn{3}{|c|}{ Light damage level } & \multicolumn{3}{|c|}{ Moderate damage level } \\
\hline & $\mathrm{PGA}_{16}$ & $\mathrm{~S}_{\mathrm{a}}\left(\mathrm{T}_{1}\right)_{16}$ & $\mathrm{CAV}_{16}$ & $\mathrm{PGA}_{16}$ & $\mathrm{~S}_{\mathrm{a}}\left(\mathrm{T}_{1}\right)_{16}$ & $\mathrm{CAV}_{16}$ \\
\hline No damage & 0.363 & 0.708 & 0.718 & 1.088 & 2.069 & 2.612 \\
\hline Light damage & 0.362 & 0.676 & 0.711 & 1.085 & 2.007 & 2.605 \\
\hline Moderate damage & N/A & N/A & N/A & 1.047 & 1.964 & 2.602 \\
\hline
\end{tabular}

Table 10 Summary of the 50th percentile as characteristic value

\begin{tabular}{|c|c|c|c|c|c|c|}
\hline \multirow[t]{2}{*}{ Post-mainshock damage } & \multicolumn{3}{|c|}{ Light damage level } & \multicolumn{3}{|c|}{ Moderate damage level } \\
\hline & $\mathrm{PGA}_{50}$ & $\mathrm{~S}_{\mathrm{a}}\left(\mathrm{T}_{1}\right)_{50}$ & $\mathrm{CAV}_{50}$ & $\mathrm{PGA}_{50}$ & $\mathrm{~S}_{\mathrm{a}}\left(\mathrm{T}_{1}\right)_{50}$ & $\mathrm{CAV}_{50}$ \\
\hline No damage & 0.556 & 1.128 & 1.126 & 2.372 & 4.811 & 4.803 \\
\hline Light damage & 0.557 & 1.119 & 1.127 & 2.353 & 4.723 & 4.764 \\
\hline Moderate damage & N/A & N/A & N/A & 2.406 & 4.913 & 4.872 \\
\hline
\end{tabular}



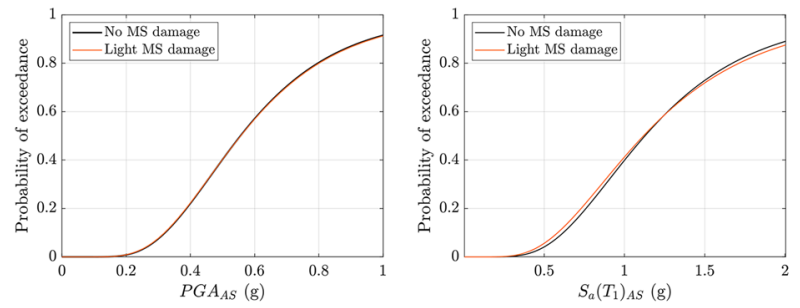

(a)

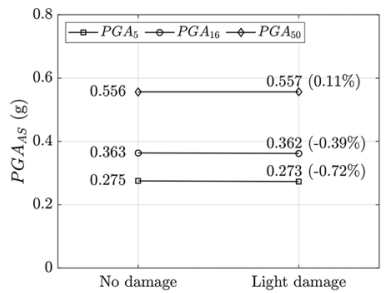

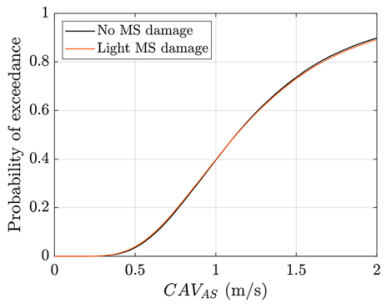

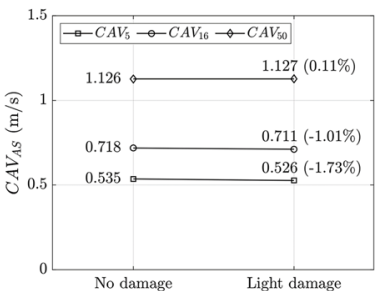

(b)

Fig. 11 Aftershock fragility curves of the steel moment frame with light post-mainshock damage at moderate damage limit state: $\mathbf{a}$ fragility curves; $\mathbf{b}$ comparisons of characteristic values
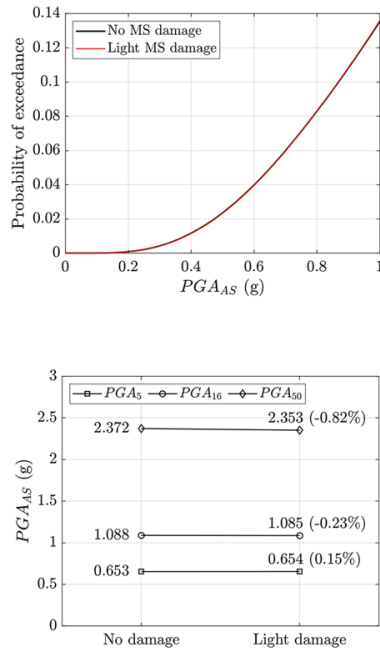

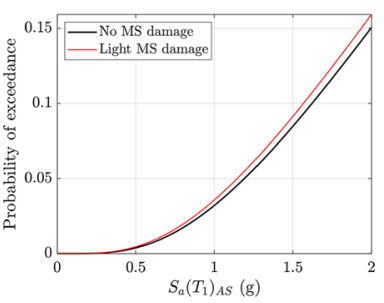

(a)

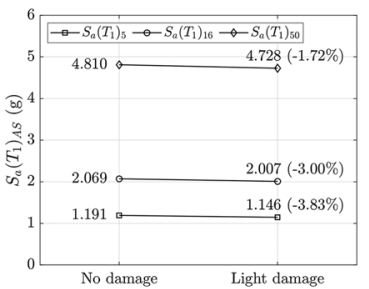

(b)
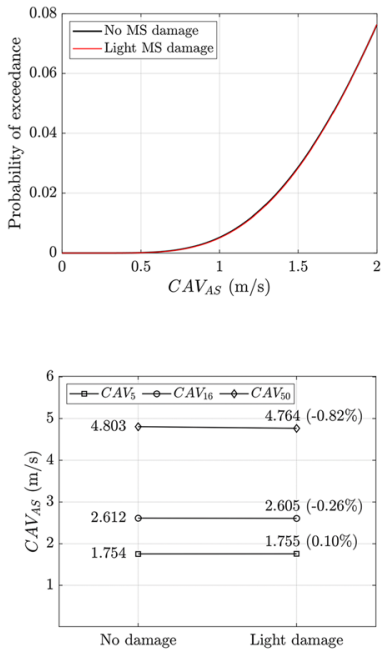

Fig. 12 Aftershock fragility curves of the steel moment frame with light post-mainshock damage at severe damage limit state: a fragility curves; $\mathbf{b}$ comparisons of characteristic values

damaged and the undamaged steel frames showed no significant differences between their IDA curves for each of the selected earthquake records, and the change in the fragility curves were very small, it can be concluded that the target light post-mainshock damage had limited influence on the steel frame's capacity to resist aftershocks. 

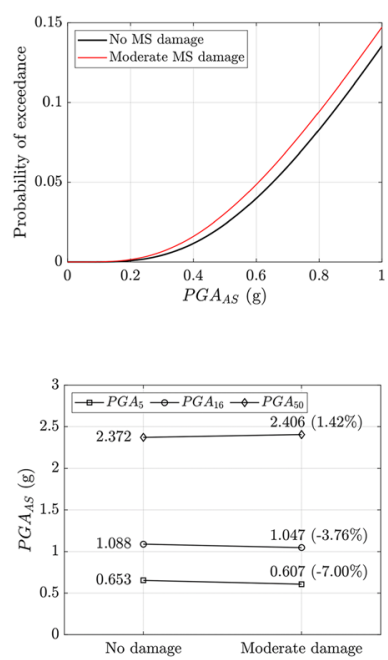

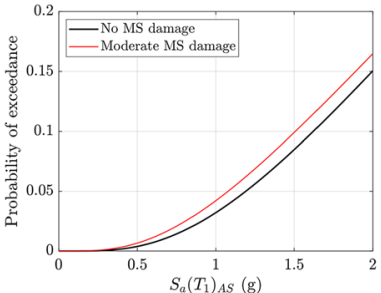

(a)

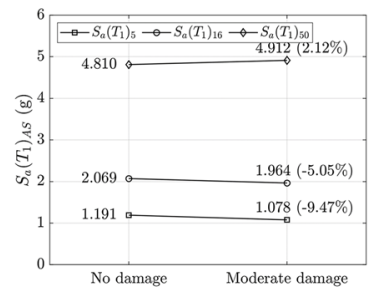

(b)
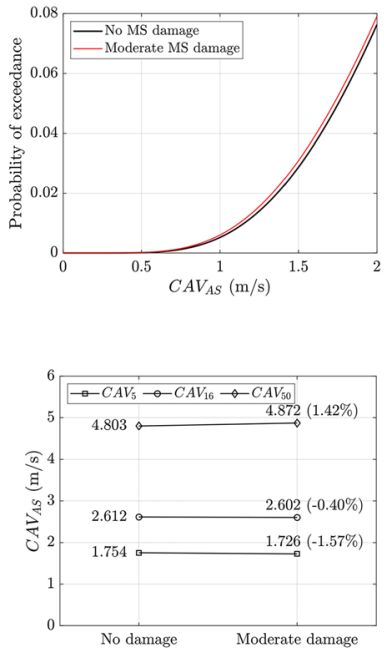

Fig. 13 Aftershock fragility curves of the steel moment frame with moderate post-mainshock damage at severe damage level: a fragility curves; $\mathbf{b}$ comparisons of characteristic values

Figure 13 shows the fragility curves of the moderately damaged steel frame at the severe damage limit state and its comparison with the performance of the undamaged steel frame. In this case, the influence of post-mainshock damage became more evident as the fragility curves showed clear increase in the failure probability within the considered range of IMs. It is noticed in Fig. 13b that for all three IMs, the 5th percentile showed the largest reduction from the case of no post-mainshock damage to the case of moderate post-mainshock damage, where $\mathrm{PGA}_{5}, \mathrm{~S}_{\mathrm{a}}\left(\mathrm{T}_{1}\right)_{5}$ and $\mathrm{CAV}_{5}$ experienced 7.00, 9.47 and $1.57 \%$ decrease, respectively. Besides, the 16th percentile tended to show a smaller reduction than the 5 th percentile, including around 5\% reduction in $\mathrm{PGA}_{16}$ and $\mathrm{S}_{\mathrm{a}}\left(\mathrm{T}_{1}\right)_{16}$, and $0.40 \%$ reduction $\mathrm{CAV}_{16}$. Lastly, the 50th percentile showed an approximately $2 \%$ increase for all the IMs considered in this study. The different results obtained from different choices of characteristic value suggested that the influence of post-mainshock damage was not constant along the entire probability distribution. As a result, it may be more appropriate to use a percentile that is within or at least not far away from the practical range of aftershock intensity, such as the 5th and 16th percentile. On the other hand, the 50th percentile, despite its ability to characterise the entire fragility function, covers also the range of aftershock intensity that is not practically relevant. The 50th percentile itself is usually associated with a very high value of intensity, e.g., the PGA $_{50}$ in Fig. $13 \mathrm{~b}$ corresponded to aftershocks with PGA of around $2.4 \mathrm{~g}$, which consequently makes it not appropriate to be adopted as a threshold value of aftershock IM.

It is also interesting to notice that in some case, the damaged steel frame showed lower failure probability than the undamaged steel frame. For example, Fig. 11b showed that the $\mathrm{PGA}_{50}$ and $\mathrm{CAV}_{50}$ both experienced $0.11 \%$ increase, Fig. $12 \mathrm{~b}$ showed 0.15 and $0.10 \%$ increase of $\mathrm{PGA}_{5}$ and $\mathrm{CAV}_{5}$, and Fig. 13b showed more than $1 \%$ increase of all 50th percentiles. Such increments were not significant, yet they still indicated that the damaged steel frame might be able to sustain larger earthquakes than the undamaged steel frame. This could be due to the fact that for some of the selected earthquake records, the steel 
frame exhibited severe hardening and a weaving behaviour in the IDA curve, as described by Vamvatsikos and Cornell (2002), which caused the damaged steel frame to fail at a higher IM than the undamaged steel frame.

The primary conclusion that can be drawn from the above assessment is that when the steel frame was with the target light post-mainshock damage, the steel frame was able to maintain its full capacity to resist aftershocks. In this case, post-quake assessment can be performed based on the undamaged initial state of the steel frame. On the other hand, the target moderate post-mainshock damage had more evident influence on the steel frame. As a result, post-quake assessment should consider reduced capacity of the steel frame, e.g., as a simplified approach applying reduction in the material property, where the reduction factor can be determined based on the comparisons of 5th, 16th and 50th percentiles as characteristic values.

\section{Conclusions}

This paper presented two parts of fragility assessment of a case study steel moment frame. In the first part, conventional fragility assessment was performed on the steel moment frame using the standardised IDA procedure, where the undamaged steel frame was directly subjected to mainshocks and MS-AS sequences. The results showed that when subjected to MS-AS sequences, the steel frame exhibited higher vulnerability than the case when it was subjected to mainshocks. A roughly $10 \%$ reduction in the medians of all three limit states was observed when comparing the fragility curves obtained under MS-AS sequences with those under mainshocks. Although the conventional fragility assessment was able to predict the overall performance of the steel frame in a complete earthquake event, it was not able to determine the intensity of aftershocks associated with progression of limit states, which was dependent on the post-mainshock damage state of the steel frame. This has brought out the necessity of performing further fragility assessment utilising state-dependent aftershock fragility curves.

In the second part, the results of evaluating aftershock IM were first presented. The evaluation of aftershock IM was conducted based on three aspects: efficiency, practicality and proficiency. It was demonstrated that the CAV was more advantageous as aftershock IM than the PGA and $\mathrm{S}_{\mathrm{a}}\left(\mathrm{T}_{1}\right)$ for all the three aspects assessed.

Following the evaluation of aftershock IMs, the state-dependent aftershock fragility curves were presented and the comparison of three potential choice of characteristic value, i.e. 5th, 16th and 50th percentile, were demonstrated. It was concluded that the target light post-mainshock damage barely influence the capacity of the steel frame to resist aftershocks. However, the influence of the target moderate post-mainshock damage was more pronounced. It was also noticed that the influence of post-mainshock damage on the variation of fragility curves was not constant for the entire probability distribution. As a result, it may be more appropriate to use the 5th and 16th percentile as the characteristic value in order to describe the change of fragility curves within the range of practical aftershock intensity.

Funding The financial support from Seismic Engineering Research Infrastructure for HITFRAMES (SERA) Project, funded within the H2020-INFRAIA-2016-2017 Framework Program of the European Commission under grant agreement No.730900 is greatly appreciated. Any opinions, findings and conclusions, or 
recommendations expressed in this paper are those of the authors and do not necessarily reflect those of SERA sponsors.

Data availability The datasets generated and analysed during the current study are available from the corresponding author on reasonable request.

\section{Declarations}

Conflict of interest The authors certify that they have NO affiliations with or involvement in any organization or entity with any financial interest (such as honoraria; educational grants; participation in speakers' bureaus; membership, employment, consultancies, stock ownership, or other equity interest; and expert testimony or patent-licensing arrangements), or non-financial interest (such as personal or professional relationships, affiliations, knowledge or beliefs) in the subject matter or materials discussed in this manuscript.

Code availability The codes generated during the current study are available from the corresponding author on reasonable request.

Open Access This article is licensed under a Creative Commons Attribution 4.0 International License, which permits use, sharing, adaptation, distribution and reproduction in any medium or format, as long as you give appropriate credit to the original author(s) and the source, provide a link to the Creative Commons licence, and indicate if changes were made. The images or other third party material in this article are included in the article's Creative Commons licence, unless indicated otherwise in a credit line to the material. If material is not included in the article's Creative Commons licence and your intended use is not permitted by statutory regulation or exceeds the permitted use, you will need to obtain permission directly from the copyright holder. To view a copy of this licence, visit http://creativecommons.org/licenses/by/4.0/.

\section{References}

American Society of Civil Engineering (ASCE) (2005) ASCE41-06. Seismic rehabilitation of existing buildings. Reston, Virginia

American Society of Civil Engineering (ASCE) (2017) ASCE41-07. Seismic evaluation and retrofit of existing buildings. Reston, Virginia

Amadio C, Fragiacomo M, Rajgelj S (2002) The effects of repeated earthquake ground motions on the non-linear response of SDOF systems. Earthq Eng Struct Dyn 32(2):291-308. https://doi.org/10. 1002/eqe. 225

Baker JW, Cornell CA (2005) A vector-valued ground motion intensity measure consisting of spectral acceleration and epsilon. Earthq Eng Struct Dyn 34(10):1193-1217. https://doi.org/10.1002/eqe. 474

Bradley BA (2011) Design seismic demands from seismic response analyses: a probability-based approach. Earthq Spectra 27(1):213-224. https://doi.org/10.1193/1.3533035

British Standard Institution (BSI) (2005) BS EN 1998-3:2005. Eurocode 8. Design of structures for earthquake resistance-part 3: Assessment and retrofitting of buildings. London

Campbell KW, Bozorgnia Y (2010) A ground motion prediction equation for the horizontal component of cumulative absolute velocity (CAV) based on the PEER-NGA strong motion database. Earthq Spectra 26(3):635-650. https://doi.org/10.1193/1.3457158

Dolšek M, Fajfar P (2008) The effect of masonry infills on the seismic response of a four-storey reinforced concrete frame-a deterministic assessment. Eng Struct 30(7):1991-2001. https://doi.org/10. 1016/j.engstruct.2008.01.001

Di Sarno L (2013) Effects of multiple earthquakes on inelastic structural response. Eng Struct 56:673681. https://doi.org/10.1016/j.engstruct.2013.05.041

Di Sarno L, Amiri S (2019) Period elongation of deteriorating structures under mainshock-aftershock sequences. Eng Struct 196:109341. https://doi.org/10.1016/j.engstruct.2019.109341

Di Sarno L, Wu JR (2020) Seismic assessment of existing steel frames with masonry infills. J Constr Steel Res 169:106040. https://doi.org/10.1016/j.jcsr.2020.106040

Eladly MM (2017) Numerical study on masonry-infilled steel frames under vertical and cyclic horizontal loads. J Constr Steel Res 138:308-323. https://doi.org/10.1016/j.jcsr.2017.07.016 
El-Dakhakhni WW, Elgaaly M, Hamid AA (2003) Three-strut model for concrete masonry-infilled steel frames. J Struct Eng 129(2):177-185

Fardis MN, Panagiotakos TB (1997) Seismic design and response of bare and masonry-infilled reinforced concrete buildings part II: infilled structures. J Earthq Eng 1(03):475-503. https://doi.org/ $10.1080 / 13632469708962375$

Filippou FC, Popov EP, Bertero VV (1983) Effects of bond deterioration on hysteretic behavior of reinforced concrete joints. Earthquake Engineering Research Center, University of California

Furtado A, Rodrigues H, Varum H, Arêde A (2018) Mainshock-aftershock damage assessment of infilled RC structures. Eng Struct 175:645-660. https://doi.org/10.1016/j.engstruct.2018.08.063

Ghazimahalleh MM (2007) Stiffness and damping of infilled steel frames. P I Civil Eng Str B 160(2):105-118. https://doi.org/10.1680/stbu.2007.160.2.105

Ghobarah A (2004) On drift limits associated with different damage levels. International workshop on performance-based seismic design, Department of Civil Engineering, McMaster University, Canada

Gupta A, Krawinkler H (1999) Seismic demands for the performance evaluation of steel moment resisting frame structures. Dissertation, Stanford University

Hatzigeorgiou GD (2010a) Ductility demand spectra for multiple near-and far-fault earthquakes. Soil Dyn Earthq Eng 30(4):170-183. https://doi.org/10.1016/j.soildyn.2009.10.003

Hatzigeorgiou GD (2010b) Behaviour factors for nonlinear structures subjected to multiple near-fault earthquakes. Comput Struct 88(5-6):309-321. https://doi.org/10.1016/j.compstruc.2009.11.006

Lee K, Foutch DA (2004) Performance evaluation of damaged steel frame buildings subjected to seismic loads. J Struct Eng 130(4):588-599. https://doi.org/10.1061/(ASCE)0733-9445(2004)130:4(588)

Li Q, Ellingwood BR (2007) Performance evaluation and damage assessment of steel frame buildings under main shock-aftershock earthquake sequences. Earthq Eng Struct Dyn 36(3):405-427. https:// doi.org/10.1002/eqe.667

Li Y, Song R, Van De Lindt JW (2014) Collapse fragility of steel structures subjected to earthquake mainshock-aftershock sequences. J Struct Eng 140(12):04014095. https://doi.org/10.1061/(ASCE) ST.1943-541X.0001019

Liberatore L, Decanini LD (2011) Effect of infills on the seismic response of high-rise RC buildings designed as bare according to Eurocode 8. Ing Sismica 3:7-23

Loulelis D, Hatzigeorgiou GD, Beskos DE (2012) Moment resisting steel frames under repeated earthquakes. Earthq Struct 3:231-248. https://doi.org/10.12989/eas.2012.3.3.231

Luco N, Cornell CA (2007) Structure-specific scalar intensity measures for near-source and ordinary earthquake ground motions. Earthq Spectra 23(2):357-392. https://doi.org/10.1193/1.2723158

Luzi L, Pacor F, Puglia R (2019) Italian Accelerometric Archive v3.0. Istituto Nazionale di Geofisica e Vulcanologia, Dipartimento della Protezione Civile Nazionale, Italy

Mazzoni S, McKenna F, Scott MH, Fenves GL (2006) OpenSees command manual. University of California, Pacific Earthquake Engineering Research Center

Menegotto M, Pinto P (1973) Method of analysis for cyclically loaded reinforced concrete plane frames including changes in geometryand non-elastic behavior of elements under combined normal force and bending. In: Proceedings of IABSE sympoium on resistance and ultimate deformability of structures acted on by well-defined repeated loads, International Association of Bridge and Structural Engineering, vol 13, pp 15-22

Markulak D, Radić I, Sigmund V (2013) Cyclic testing of single bay steel frames with various types of masonry infill. Eng Struct 51:267-277. https://doi.org/10.1016/j.engstruct.2013.01.026

Najarkolaie KF, Mohammadi M, Fanaie N (2017) Realistic behavior of infilled steel frames in seismic events: experimental and analytical study. Bull Earthq Eng 15(12):5365-5392. https://doi.org/10. 1007/s10518-017-0173-z

National Research Institute for Earth Science and Disaster Resilience (NIED) (2019) NIED K-NET, KiK-net. National Research Institute for Earth Science and Disaster Resilience, Japan.

O'Hara TF, Jacobson JP (1991) Standardization of the cumulative absolute velocity. Electric Power Research Institute, Palo Alto, CA

Padgett JE, Nielson BG, DesRoches R (2008) Selection of optimal intensity measures in probabilistic seismic demand models of highway bridge portfolios. Earthq Eng Struct Dyn 37(5):711-725. https://doi.org/10.1002/eqe.782

Raghunandan M, Liel AB, Luco N (2005) Aftershock collapse vulnerability assessment of reinforced concrete frame structures. Earthq Eng Struct Dyn 44(3):419-439. https://doi.org/10.1002/eqe.2478

Rossetto T, Elnashai A (2005) A new analytical procedure for the derivation of displacement-based vulnerability curves for populations of RC structures. Eng Struct 27(3):397-409. https://doi.org/10. 1016/j.engstruct.2004.11.002 
Ruiz-García J, Aguilar JD (2015) Aftershock seismic assessment taking into account post-mainshock residual drifts. Earthq Eng Struct Dyn 44(9):1391-1407. https://doi.org/10.1002/eqe.2523

Ruiz-García J, Negrete-Manriquez JC (2011) Evaluation of drift demands in existing steel frames under as-recorded far-field and near-fault mainshock-aftershock seismic sequences. Eng Struct 33(2):621-634. https://doi.org/10.1016/j.engstruct.2010.11.021

Ruiz-García J, Yaghmaei-Sabegh S, Bojórquez E (2018) Three-dimensional response of steel momentresisting buildings under seismic sequences. Eng Struct 175:399-414. https://doi.org/10.1016/j. engstruct.2018.08.050

Seyhan E, Stewart JP, Ancheta TD, Darragh RB, Graves RW (2014) NGA-West2 site database. Earthq Spectra 30(3):1007-1024. https://doi.org/10.1193/062913EQS180M

Shome N, Cornell CA, Bazzurro P, Carballo JE (1998) Earthquakes, records, and nonlinear responses. Earthq Spectra 14(3):469-500. https://doi.org/10.1193/1.1586011

Tasnimi AA, Mohebkhah A (2011) Investigation on the behavior of brick-infilled steel frames with openings, experimental and analytical approaches. Eng Struct 33(3):968-980. https://doi.org/10. 1016/j.engstruct.2010.12.018

Vamvatsikos D, Cornell CA (2002) Incremental dynamic analysis. Earthq Eng Struct Dyn 31(3):491514. https://doi.org/10.1002/eqe.141

Yekrangnia M, Mohammadi M (2017) A new strut model for solid masonry infills in steel frames. Eng Struct 135:222-235. https://doi.org/10.1016/j.engstruct.2016.10.048

Yeo GL, Cornell CA (2005) Stochastic characterization and decision bases under time-dependent aftershock risk in performance-based earthquake engineering. Pacific Earthquake Engineering Research Center, University of California

Publisher's Note Springer Nature remains neutral with regard to jurisdictional claims in published maps and institutional affiliations. 